\title{
Forced expiratory volume in one second: not just a lung function test but a marker of premature death from all causes
}

\author{
R.P. Young*, R. Hopkins" and T.E. Eaton ${ }^{\#}$
}

ABSTRACT: The clinical utility of spirometric screening of asymptomatic smokers for early signs of air flow limitation has recently come under review. The current authors propose that reduced forced expiratory volume in one second (FEV1) is more than a measure of airflow limitation, but a marker of premature death with broad utility in assessing baseline risk of chronic obstructive pulmonary disease (COPD), lung cancer, coronary artery disease and stroke, collectively accounting for $70-80 \%$ of premature death in smokers.

Reduced FEV 1 identifies undiagnosed COPD, has comparable utility to that of serum cholesterol in assessing cardiovascular risk and defines those smokers at greatest risk of lung cancer. As such, reduced FEV1 should be considered a marker that identifies smokers at greatest need of medical intervention.

Smoking cessation has been shown to attenuate FEV 1 decline and, if achieved before the age of 45-50 yrs, may not only preserve FEV1 within normal values but substantially reduce cardiorespiratory complications of smoking.

Recent findings suggest inhaled drugs (bronchodilators and corticosteroids), and possibly statins, may be effective in reducing morbidity and mortality in patients with chronic obstructive pulmonary disease. The current authors propose that spirometry has broad utility in identifying smokers who are at greatest risk of cardiorespiratory complications and greatest benefit from targeted preventive strategies, such as smoking cessation, prioritised screening and effective pharmacotherapy.

KEYWORDS: Baseline risk, chronic obstructive pulmonary disease, epidemiology, lung function, premature death, spirometry

n 1977, FLETCHER and PETO [1] published their seminal paper in the British Medical Journal, demonstrating the existence of a subgroup of smokers highly susceptible to accelerated decline in lung function, as measured by forced expiratory volume in one second (FEV1). With continued smoking, these smokers developed chronic obstructive pulmonary disease (COPD) and died prematurely. Subsequent studies have shown that reduced FEV1 in smokers is not only associated with a significantly increased risk of COPD, but also lung cancer, acute coronary syndromes and stroke [2-8], which collectively account for 70-80\% of premature death in smokers $[9,10]$. Importantly, if susceptible smokers quit before reaching a critical threshold, this accelerated decline in FEV1 could be attenuated to that of nonsmokers, thereby preserving lung function, reducing morbidity and preventing premature death $[1,11]$. The current authors argue that FEV1 is more than a test of lung function essential in quantifying airflow limitation, it is a marker of premature death with broad clinical utility in baseline risk assessment and possible prevention of both respiratory (COPD and lung cancer) and cardiovascular (coronary artery disease (CAD) and stroke) diseases. It has been noted that reduced FEV1 may also reflect restrictive lung disease that: 1) is not infrequently found in population studies; 2 ) may in part be due to nonpulmonary factors such as obesity and heart failure (particularly in nonsmokers); and 3) remains a marker of overall mortality [12]. For the purposes of the present study, the current authors have focused on the clinical utility of
AFFILIATIONS

${ }^{*}$ Dept of Medicine, University of Auckland, and

\#Respiratory Services, Green Lane Hospital, Auckland, New Zealand.

CORRESPONDENCE

R.P. Young

Dept of Medicine

Auckland Hospital

Private Bag 92019

Auckland

New Zealand

Fax: 6496310711

E-mail: roberty@adhb.govt.nz

Received:

February 222007

Accepted after revision:

July 222007

STATEMENT OF INTEREST

None declared.

European Respiratory Journal

Print ISSN 0903-1936

Online ISSN 1399-3003 
spirometry in smokers where obstructive lung disease is most relevant.

\section{THE NATURAL HISTORY OF LUNG FUNCTION DECLINE} In 1977, FLETCHER and PETO [1] published a prospective study that monitored decline in FEV1 and made several key observations. First, in contrast to nonsmokers, smokers who continued to smoke showed a wide variability in FEV1 decline (fig. 1a). This decline ranged from normal age-related decline (as seen in lifelong nonsmokers) to a steep decline resulting in COPD, disabling breathlessness and premature death. Based on these observations, they proposed that a subgroup of smokers were "susceptible", characterised by an accelerated FEV1 decline leading to COPD and premature death. Recent studies suggest this decline is likely to occur in discrete steps, secondary to pulmonary insults, such as chest infections (or COPD exacerbations), potentially attenuated by preventive or early treatment [13]. Studies by BurRows et al. [14] and DOCKERY et al. [15] further clarified the distribution of FEV1 according to smoking exposure dose. Despite being crosssectional studies, both showed that after an accumulated 2030 pack-yr history of smoking, the normal unimodal distribution of FEV1 seen in light or never-smokers (fig. 2a) had skewed left towards reduced lung function. After $\geqslant 60$ pack-yrs of smoking, the unimodal distribution had changed to something approaching a bimodal or even trimodal distribution (fig. 2b). Based on these studies and a recently published prospective study [16], the current authors conclude that $\sim 60 \%$ of lifelong smokers maintained near-normal FEV1 ("resistant"), while $\sim 10-20 \%$ suffered mild loss of FEV1 ("intermediate") and the remaining $20-30 \%$ of smokers had significant loss of FEV1 to levels consistent with COPD ("susceptible"; fig. 2b). Given that the smokers in the studies by BurRows et al. [14] and DOCKERY et al. [15] had the same heavy smoking history (>60 pack-yrs), the widely differing lung function clearly indicates that factors other than smoking exposure dose per se are at play in determining which smokers develop severe COPD and die prematurely.

The second observation made by FleTCHER and PeTO [1] was that in the early stages, FEV1 decline is insidious, with smokers generally remaining asymptomatic until FEV1 has fallen to $\leqslant 50 \%$ of its maximal value, well below the threshold defining a spirometrically based diagnosis of COPD $[17,18]$. The third, and probably most important, observation was that if a susceptible smoker quit smoking, the rate of decline in FEV1 could reduce towards that of a lifelong nonsmoker (fig. 1b). Importantly, if the majority of smokers achieved smoking cessation before $40-45$ yrs of age, their FEV1 can be maintained within normal age-referenced values. This observation has been confirmed in other prospective studies [11] and is central to the current authors' hypothesis that because FEV1 decline can be attenuated by smoking cessation, it can be considered "modifiable". Crucially, these observations show that the earlier a susceptible smoker quits, the greater the preservation of FEV1, the greater the delay to debilitating breathlessness and the longer their survival.

\section{REDUCED FEV1 AND FUTURE MORBIDITY/MORTALITY Smoking, FEV1 and COPD}

COPD is almost invariably a disease that results from smoking. Of those affected, $90 \%$ have a current or past history of smoking exposure. The lifetime risk of COPD in smokers is estimated to be $20 \%[2,14]$, although if a mild degree of airflow limitation is included (Global Initiative for Chronic Obstructive Lung Disease stage 1 COPD) then up to $50 \%$ of smokers maybe affected [19]. As decline in lung function is so insidious, COPD commonly remains undetected until quite late (if indeed at all), and explains why as many as $50 \%$ of patients with COPD remain undiagnosed and, therefore, untreated [19]. This underscores the importance of spirometry in the early identification of susceptible smokers.

\section{Smoking, FEV1 and lung cancer}

Lung cancer is also almost invariably a disease of smokers. Of those diagnosed, $85-90 \%$ have a current or past history of smoking exposure. Studies show that, after adjustment for age and smoking, reduced FEV1 is associated with an increased risk of lung cancer [2, 20-22]. Smokers with reduced FEV1 carry as much as a five to six-fold risk of lung cancer compared with smokers with normal lung function [2, 20-22]. Other factors identifying a smoker at high risk of lung cancer include: the magnitude of smoking exposure ( $>30$ pack-yrs or $>30$ yrs duration); age >50 yrs; family history of lung cancer; and previous asbestos exposure [23]. In a primary care screening study, these factors, in combination with impaired lung function, were shown to cost-effectively identify smokers or ex-smokers at high risk of lung cancer for computed tomography (CT) screening purposes [23].

\section{Smoking, FEV1 and coronary artery disease}

Smoking is one of the most important risk factors for coronary artery disease, along with elevated cholesterol and blood pressure. Interestingly, the younger the age of CAD onset, the greater the importance of smoking. Several studies have now shown that the smoking prevalence in premature CAD (age $<40-50 \mathrm{yrs}$ ) is as much as $80 \%$. What is generally not appreciated is that a reduced FEV1 is a strong marker for CAD [3-5] and mortality from cardiovascular disease [5-7]. Indeed for males, the combination of reduced FEV1 and smoking exposure are better predictors of future mortality from heart disease than serum cholesterol levels [10]. In the present study, where FEV1 was compared with traditional risk factors, it is striking that reduced FEV1 ranks second only to smoking, well above blood pressure, social class and cholesterol $[10,19]$ as a predictor for all-cause mortality in both males and females.

To illustrate to what extent lung function is relevant to cardiovascular mortality, the current authors refer to data from two studies that showed, after adjustment for other variables, that reduced FEV1 is more important than smoking exposure (figs $3 \mathrm{a}$ and b). Among smokers of comparable smoking exposure, reduced FEV1 was associated with up to three to four-fold greater cardiovascular mortality [6, 7]. Remarkably, this effect also extends to nonsmokers, in whom poor FEV1 predicts a risk two to three-fold greater than that of heavy smokers with normal lung function. The current authors conclude that FEV1 is an important marker of future cardiovascular mortality and that its effects on mortality are both independent from and synergistic with those from smoking. 

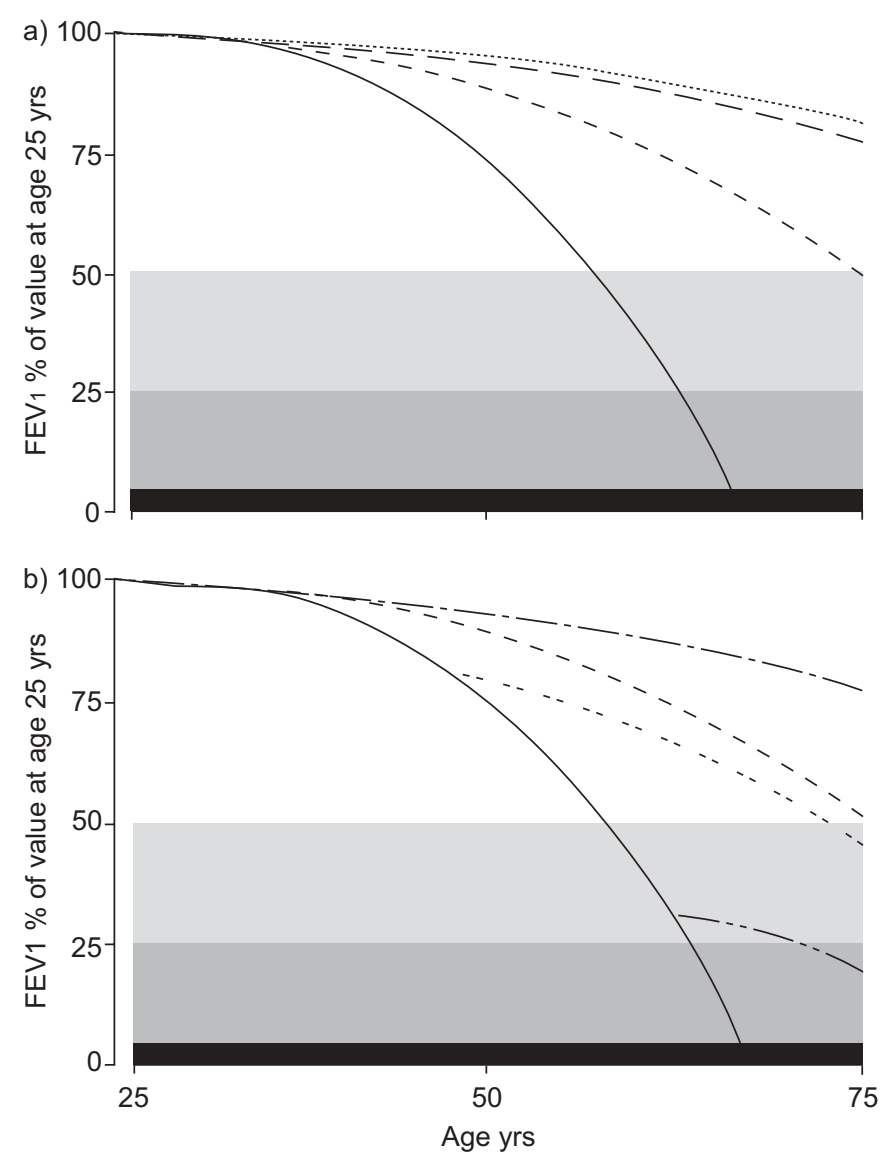

FIGURE 1. Forced expiratory volume in one second (FEV 1 1) decline in a) neversmokers and smokers and b) in susceptible smokers after quitting smoking. death; : : severe disability; 1 : onset of symptoms. — : susceptible smokers (chronic obstructive pulmonary disease); - - - - in intermediate smokers: …....... never smokers; - - - - - : not susceptible to smoke; - - _ - - - -: resistant smokers -- -- -- --: susceptible smoker, stopped smoking at age $45 \mathrm{yrs} ; \ldots$ susceptible smoker, stopped smoking at age 65 yrs. Modified from [1].

\section{Smoking, FEV 1 and overall mortality}

A consistent observation in all these epidemiological studies is that smokers with reduced FEV1 have considerably higher morbidity and mortality than smokers with normal lung function. The basis of this observation is not yet understood. This may be an epiphenomenon, reflecting the shared risk factor of smoking, but is otherwise unrelated. Alternatively, it may be indicative of an underlying susceptibility to chronic inflammation [19] that has now been implicated in all three diseases [24-26]. Smoking initiates and maintains an inflammatory stimulus which is ubiquitous, affecting lung epithelium and arterial endothelium. However, factors specific to susceptible smokers, such as aberrant cellular response and repair processes [19], may, over time, promote airway fibrosis and lung destruction in COPD [24], failed apoptosis in lung cancer [25] and plaque instability in acute coronary syndromes [26]. Accordingly, the lungs function as the body's most important "sampler and filter" of the environment, and FEV1 as a barometer of the body's response to systemic inflammation from chronic aero-pollutant exposure, in particular smoking.
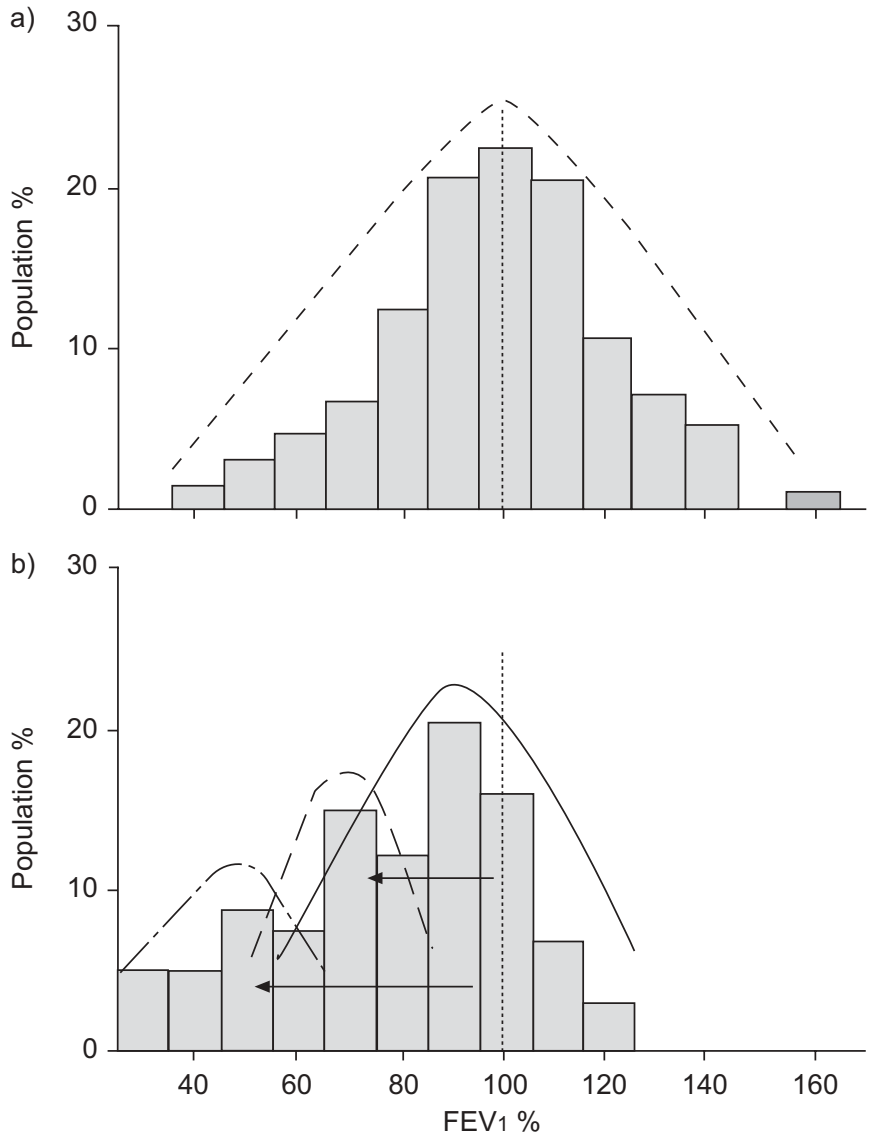

FIGURE 2. Distribution of forced expiratory volume in one second (FEV1) \% predicted in a) nonsmokers and light smokers and b) heavy smokers. . . . normal distribution; __ : resistant smokers; - - - - -: intermediate smokers; - — - - : susceptible smokers. Modified from [14].

\section{REDUCED FEV1 AND CLINICAL UTILITY \\ Smoking cessation}

There is no dispute that spirometry is integral to the screening, diagnosis and monitoring of respiratory disease. However, debate remains as to the benefit of screening to detect early sub-clinical COPD [27]. Several studies have demonstrated the importance of identifying asymptomatic smokers with impaired lung function, and the subsequent improvement in smoking cessation rates [28, 29]; although this has not been a universal finding [27]. None of these studies utilised the wider implications of identifying smokers susceptible to reduced FEV1. Specifically, apart from diagnosing COPD early in its natural history, smokers with reduced lung function are also at high risk of lung cancer and premature cardiovascular death. This observation has not been widely integrated into these cessation studies and may be important in motivating smokers to quit given that lung cancer and heart attack are perceived as significantly more life-threatening than COPD. The smoking cessation rate of patients identified with COPD is only $5-15 \%$, comparable to that seen in healthy smokers motivated to quit and given nicotine replacement therapy [30]. In contrast, 50\% of smokers who suffer heart attacks [31] and up to $40 \%$ of smokers identified with suspicious lung nodules on spiral CT scans quit smoking [32]. This suggests that when smokers are 

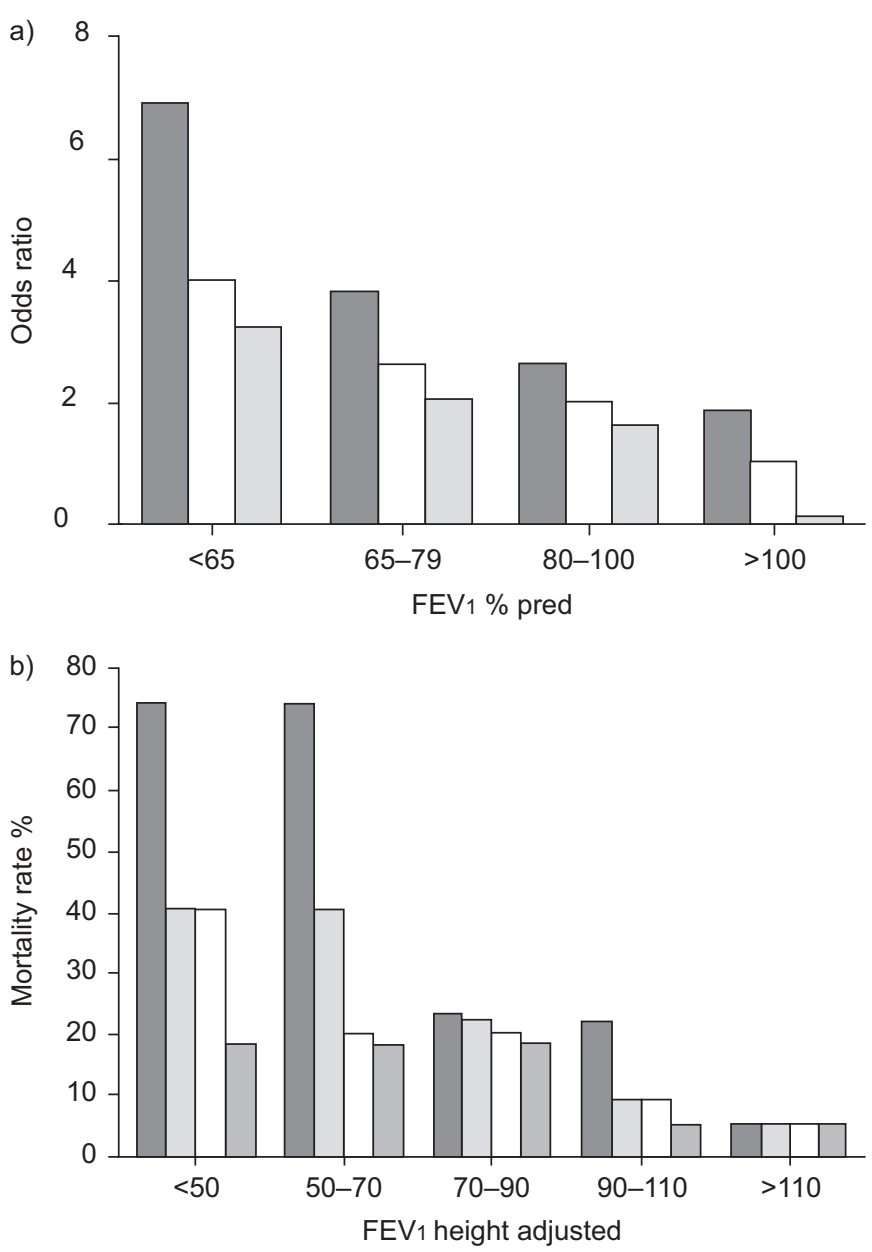

FIGURE 3. Relationship between forced expiratory volume in one second (FEV1), smoking status and a) odds ratio for cardiovascular mortality and b) all cause mortality rate. a) $\mathbf{\square}$ : current smoker; $\square$ : ex-smoker; $\square$ : never-smoker. b) $\mathbf{\square}$ heavy smoker; 1 : : moderate smoker; $\square$ : ex-smoker; 1 : non-smoker. a, b) Modified from [6] and [7], respectively.

confronted with these "more lethal" complications, significantly greater rates of cessation can be achieved. This is most likely explained by the combined effects of increasing motivation towards cessation (by enhancing motivational tension and triggering action) [33], and overcoming the natural tendency of optimistic bias (denial of one's own risk), considered one of the most important barriers in smoking cessation [34].

\section{Baseline risk assessment}

Existing public health strategies for smoking prevention currently focus on tobacco advertising restrictions, health warnings, taxes and smoking bans in public places. These population-based strategies should be augmented with individual patient education, utilising baseline risk assessment that personalises and quantifies that risk. This has become the basis of prevention of CAD, where risk factors are measured and individual treatments or lifestyle interventions are initiated as necessitated by the degree of risk identified. Although it has been shown that smoking rates have been successfully reduced with the nontargeted population-based strategies described previously (akin to the population prevention axiom [35]),
FLeTCher and Peto [1] and others have shown that risk from smoking is concentrated in only a proportion of smokers [16]. With relevance to outcome, it has recently been argued that the broader benefits of population-based prevention strategies may be inferior to those in which an intervention is targeted at those with high baseline risk [35]. Adopting this approach, primary prevention of smoking-related complications would target (or prioritise) those at greatest risk based on reduced FEV1 in conjunction with other risk factors. This is analogous to existing primary prevention strategies in cardiovascular disease where those with elevated blood pressure, blood glucose or serum cholesterol are identified by widespread screening and aggressively treated with lifestyle and/or pharmacological interventions. Just as the aim in CAD prevention is to maintain blood pressure and serum cholesterol at near-normal levels, maintaining FEV1 within the normal range (\% of predicted) could be viewed in the same way. In addition to its potential clinical utility in smoking cessation, impaired lung function provides a useful screening tool (and "teachable moment") for identifying smokers most at risk of lung cancer, heart attack and stroke. In this setting, reduced FEV1 could help prioritise which smokers might benefit most from aggressive screening for these smoking related complications. Recently, a study has shown that screening for lung cancer using spiral CT scans is more costeffective when smokers and ex-smokers are prioritised using impaired FEV1 in combination with other risk factors for lung cancer [23].

\section{Disease prevention}

Given the importance of reduced FEV1 in cardiovascular risk, the current authors support others who propose that it be used in conjunction with existing risk markers [36], such as blood pressure and serum cholesterol, to assess risk and target preventive treatment. Improved outcome from such an approach is suggested by three recent large observational studies showing that patients with COPD who took statins (hydroxymethyl-glutaryl CoA reductase inhibitors) had substantial reductions in both morbidity and mortality, compared with those with COPD who did not [37-39]. Strikingly, those with COPD who took statins had a $\geqslant 50 \%$ reduction in allcause mortality [37-39], 50\% reduction in myocardial infarction [37] and 30\% reduction in hospitalisation from COPD [37]. Moreover, in a recently reported nonrandomised study of lung function screening in smokers and ex-smokers, those taking statins had an $85 \%$ reduction in annual FEV1 decline and $35 \%$ reduction in COPD-related hospitalisation, compared with those not taking statins [40]. These observational data are remarkably consistent and suggest the mortality benefit in COPD patients taking statins was approximately two-fold greater than the mortality benefit seen with inhaled corticosteroid therapy ( $\geqslant 25 \%$ reduction) [41] or corticosteroid therapy combined with long-acting bronchodilators ( $\geqslant 35 \%$ reduction) [42]. Moreover, the reduction in hospitalisation with the statin therapy was comparable to that achieved with local-acting inhaled corticosteroids [43]. Perhaps of greater significance was that reduction in myocardial infarction seen with the statin therapy was two-fold greater in patients with COPD than in the coronary artery primary prevention studies [44]. Finally, statin use has also been associated with reduced risk of lung cancer [45]. As these statin studies were only observational 
studies [37-40, 45], the potential for confounding exists and randomised clinical trial data will be required to confirm these interesting findings.

There is now considerable evidence suggesting statins have immunomodulatory effects that could attenuate the inflammatory effects of smoking on the lung [46], not just the arteries. These include reducing neutrophil migration, cytokine production, adverse matrix remodelling and small airways inflammation [47]. The current authors suggest that identifying smokers with significant air flow limitation (FEV $1<70 \%$ pred) could be considered analogous (in terms of future cardiovascular risk) to identifying those with elevated cholesterol (together with other CAD risk factors), thus prompting consideration of primary preventive treatment with statin therapy in those with multiple risk factors. Given the substantial risk of CAD conferred by a reduced FEV1, it is not surprising that patients with COPD appear to gain greater cardiovascular benefit from statin therapy than those with normal lung function from the primary prevention studies.

\section{IS POPULATION-WIDE SCREENING WITH SPIROMETRY} A REALISTIC GOAL?

It is noteworthy that respiratory specialist societies are globally unified in their recommendation that all smokers $>40-45$ yrs of age should be screened using spirometry. This age band is important in the natural history of lung function decline as 40 50 yrs of age is a time-frame when the spirometric threshold of COPD diagnosis usually begins to be reached [1] and when smoking cessation is most beneficial [9]. To achieve this goal it is essential that quality spirometry be widely available and accessible to primary care providers [48]. To facilitate this, spirometers are now available that are highly portable, inexpensive and utilise technology that obviates the need for calibration. Importantly, the new generation of spirometers provides immediate quality feedback, which has been identified as the key limitation of spirometry performed in the primary care setting [49]. Acknowledging the difficulties of performing spirometry in general practice, studies have shown that outsourcing of spirometry to community-based allied healthcare professionals who are specifically trained and dedicated to spirometric measurement, is a viable approach to enhancing accessibility to spirometry in the community [50] and improves primary care management of COPD [51].

\section{DISCUSSION}

There is overwhelming evidence from large scale epidemiological studies demonstrating impaired lung function, characterised by reduced FEV1, is a powerful marker of future morbidity and mortality. Specifically, reduced FEV1 not only establishes the presence and severity of COPD, leading to improved treatment [51], but is a powerful predictor of increased risk of lung cancer, cardiovascular disease and premature death. The present study proposes that such knowledge could lead to improved (and better targeted) patient care, with improved clinical outcomes.

Evidence from several epidemiological studies has shown that FEV1 is a potentially modifiable marker (fig. 1b), specifically that its rate of decline can be attenuated by smoking cessation. Although one might challenge the concept that FEV1 (or FEV1 decline) be viewed as modifiable, only loosely analogous to serum cholesterol and blood pressure in the current paradigm of cardiovascular preventive medicine, the current authors believe it remains a helpful concept in empowering doctors (and their patients) to commit to and embrace smoking cessation and smoking cessation interventions. There are now many intervention and observational studies that have irrefutably established that risk of COPD, lung cancer and CAD can be substantially reduced by smoking cessation. Moreover, studies suggest that if smoking cessation is achieved by $40-45$ yrs of age then not only can lung function be maintained at or near normal levels for the majority of prior smokers but, albeit independently, the risk of these smokingrelated complications may be virtually reduced to those of a lifelong nonsmoker [9]. This raises the question as to if (or how) these two outcomes from smoking cessation might be related. Although it is accepted that the preservation of lung function after smoking cessation confers protection from COPD-related mortality, it is not clear if this confers a reduction in cardiovascular mortality. Many studies suggest that they may be related through an inflammatory mechanism $[3,19,52]$. It is possible that smoking cessation, particularly early in the habit, may attenuate inflammatory processes in the respiratory and arterial tree, reducing lung function decline and reducing atheromatous plaque progression and instability. Such a hypothesis is supported (but not confirmed) by a study that showed a borderline significant interactive effect between reduced FEV1 and smoking cessation on cardiovascular mortality $[53,54]$.

It is not enough to promote smoking cessation to all smokers. The current authors suggest greater effort needs to be made to recognise susceptible smokers, identified through greater utilisation of FEV1 screening. Those smokers with increased susceptibility should be aggressively assisted to quit smoking, as even modest gains in smoking cessation in this high-risk group would be expected to translate into substantial reductions in population morbidity and mortality [55]. Such a targeted approach typifies the 80:20 rule, where $80 \%$ of the gains would come from smoking cessation in those $20 \%$ of smokers who are most susceptible. The current authors also propose that FEV1 screening be widely utilised in baseline risk assessment of smokers for primary prevention of COPD, lung cancer, $\mathrm{CAD}$ and stroke in order to personalise risk, prioritise screening or consider initiating therapeutic interventions.

In conclusion, this is likely to be a cost-effective approach augmenting existing population based strategies intended to reduce smoking-related complications and premature death.

\section{REFERENCES}

1 Fletcher C, Peto R. The natural history of chronic airflow obstruction. Br Med J 1977; 1: 1645-1648.

2 Tockman MS, Anthonisen NR, Wright EC, Donithan MG. Airways obstruction and the risk for lung cancer. Ann Intern Med 1987; 106: 512-518.

3 Sin DD, Wu LL, Man SFP. The relationship between reduced lung function and cardiovascular mortality: a population-based study and a systematic review of the literature. Chest 2005; 127: 1952-1959. 
4 Knot UN, Khot MB, Bajzer CT, et al. Prevalence of conventional risk factors in patients with coronary artery disease. JAMA 2003; 290: 898-904.

5 Stavem K, Aaser E, Sandvik L, et al. Lung function, smoking and mortality in a 26-year follow-up of healthy middle-aged males. Eur Respir J 2005; 25: 618-625.

6 Tockman MS, Comstock GW. Respiratory risk factors and mortality: longitudinal studies in Washington County, Maryland. Am Rev Respir Dis 1989;140 S56-S63.

7 Olofson J, Skoogh BE, Bake B, Svärdsudd K. Mortality related to smoking habits, respiratory symptoms and lung function. Eur J Respir Dis 1987; 71: 69-76.

8 Truelsen T, Prescott E, Lange P, Schnohr P, Boysen G. Lung function and risk of fatal and non-fatal stroke. The Copenhagen City Heart Study. Int J Epidemiol 2001; 30: 145-151.

9 Doll R, Peto R, Wheatley K, Gray R, Sutherland I. Mortality in relation to smoking: 40 years' observations on male British doctors. BMJ 1994; 309: 901-911.

10 Hole DJ, Watt GC, Davey-Smith G, Hart CL, Gillis CR, Hawthorne VM. Impaired lung function and mortality risk in men and women: findings from the Renfrew and Paisley prospective population study. BMJ 1996; 313: 711-715.

11 Anthonisen NR, Connett JE, Murray RP. Smoking and lung function of Lung Health Study participants after 11 years. Am J Respir Crit Care Med 2002; 166: 675-679.

12 Mannino DM, Holguin F, Pavlin BI, Ferdinands JM. Risk factors for prevalence of and mortality related to restriction on spirometry: findings from the First National Health and Nutrition Examination Survey and follow-up. Int J Tuberc Lung Dis 2005; 9: 613-621.

13 Donaldson GC, Seemungal TAR, Patel IS, Lloyd-Owen SJ, Wilkinson TM, Wedzicha JA. Longitudinal changes in the nature, severity and frequency of COPD exacerbations. Eur Respir J 2003; 22: 931-936.

14 Burrows B, Knudson RJ, Cline MG, Lebowitz MD. Quatitative relationships between cigarette smoking and ventilatory function. Am Rev Respir Dis 1977; 115: 195-205.

15 Dockery DW, Speizer FE, Ferris BG, Ware JH, Louis TA, Spiro A. Cumulative and reversible effects of lifetime smoking on simple tests of lung function in adults. Am Rev Respir Dis 1988; 137: 286-292.

16 Løkke A, Lange P, Scharling H, Vestbo J. Developing COPD: a 25 year follow up study of the general population. Thorax 2006; 61: 935-939.

17 Siafakas NM, Vermeire P, Pride NB, et al. Optimal assessment and management of chronic obstructive pulmonary disease (COPD). The European Respiratory Society Task Force. Eur Respir J 1995; 8: 1398-1420.

18 Global Initiative for Chronic Obstructive Lung Diseases. www.goldcopd.com. Date last revised: 2006.

19 Mannino DM, Watt G, Hole D, et al. The natural history of chronic obstructive pulmonary disease. Eur Respir J 2006; 27: 627-643.

20 Skillrud DM, Offord KP, Miller RD. Higher risk of lung cancer in chronic obstructive pulmonary disease. A prospective, matched, controlled study. Ann Int Med 1986; 105: 503-507.

21 Mannino DM, Aguayo SM, Petty TL, Redd SC. Low lung function and incident lung cancer in the United States: data from the first National Health and Nutrition Examination Survey follow-up. Arch Int Med 2003; 163: 1475-1480.
22 Wasswa-Kintu S, Gan WQ, Man SF, Pare PD, Sin DD. Relationship between reduced forced expiratory volume in one second and the risk of lung cancer: a systematic review and meta-analysis. Thorax 2005; 60: 570-575.

23 Bechtel JJ, Kelley WA, Coons TA, Klein MG, Slagel DD, Petty TL. Lung cancer detection in patients with airflow obstruction identified in a primary care outpatient practice. Chest 2005; 127: 1140-1145.

24 Hogg JC, Chu F, Utokaparch S, et al. The nature of smallairway obstruction in chronic obstructive pulmonary disease. N Engl J Med 2004; 350: 2645-2653.

25 Petty TL. Are COPD and lung cancer two manifestations of the same disease? Chest 2005; 128: 1895-1897.

26 Hansson GK, Libby P, Schönbeck U, Yan ZQ. Innate and adaptive immunity in the pathogenesis of atherosclerosis. Circ Res 2002; 91: 281-291.

27 Boushey H, Enright P, Samet J. Spirometry for chronic obstructive pulmonary disease case finding in primary care? Am J Respir Crit Care Med 2005; 172: 1481-1482.

28 Górecka D, Bednarek M, Nowiński A, Puścińska E, GoljanGeremek A, Zieliński J. Diagnosis of airflow limitation combined with smoking cessation advice increases stopsmoking rate. Chest 2003; 123: 1916-1923.

29 Bednarek M, Gorecka D, Wielgomas J, et al. Smokers with airway obstruction are more likely to quit smoking. Thorax 2006; 61: 869-873.

30 Wagena EJ, van der Meer RM, Ostelo RJ, Jacobs JE, van Schayck CP. The efficacy of smoking cessation strategies in people with chronic obstructive pulmonary disease: results from a systematic review. Respir Med 2004; 98: 805-815.

31 Rea TD, Heckbert SR, Kaplan RC, Smith NL, Lemaitre RN, Psaty BM. Smoking status and risk for recurrent coronary events after myocardial infarction. Ann Intern Med 2002; 137: 494-500.

32 Townsend CO, Clark MM, Jett JR, et al. Relation between smoking cessation and receiving results from three annual spiral chest computed tomography scans for lung carcinoma screening. Cancer 2005; 103: 2154-2162.

33 West $\mathrm{R}$, Sohal $\mathrm{T}$. Catastrophic pathways to smoking cessation: findings from national survey. BMJ 2006; 332: 458-460.

34 Weinstein ND, Marcus SE, Moser RP. Smokers' unrealistic optimism about their risk. Tob Control 2005; 14: 55-59.

35 Manuel DG, Lim J, Tanuseputro P, et al. Revisiting Rose: strategies for reducing coronary heart disease. BMJ 2006; 332: 659-662.

36 Hunninghake DB. Cardiovascular disease in chronic obstructive pulmonary disease. Proc Am Thorac Soc 2005; 2: 44-49.

37 Mancini GBJ, Etminan M, Zhang B, Levesque LE, FitzGerald JM, Brophy JM. Reduction of morbidity and mortality by statins, angiotensin-converting enzyme inhibitors, and angiotensin receptor blockers in patients with chronic obstructive pulmonary disease. J Am Coll Cardiol 2006; 47: 2554-2560.

38 Søyseth V, Brekke PH, Smith P, Omland T. Statin use is associated with reduced mortality in COPD. Eur Respir J 2007; 29: 279-283.

39 Frost FJ, Petersen H, Tollestrup K, Skipper B. Influenza and COPD mortality protection as pleiotropic, dose-dependent effects of statins. Chest 2007; 131: 1006-1012. 
40 Younis WG, Chbeir EA, Daher NN, Deraika TA, Kinasewitz GT, Kedissi JI. Statins protect smokers from lung disease. Chest 2006; 130: 180S.

41 Sin DD, Wu L, Anderson JA, et al. Inhaled corticosteroids and mortality in chronic obstructive pulmonary disease. Thorax 2005; 60: 992-997.

42 Mapel DW, Nelson LS, Lydick E, et al. Survival of COPD patients using Advair discus, inhaled corticosteroids and salmeterol individually, inhaled corticosteroids alone, or short acting bronchodilators alone. American Thoracic Society, San Diego, 2006; A110.

43 Kiri VA, Pride NB, Soriano JB, Vestbo J. Inhaled corticosteroids in chronic obstructive pulmonary disease: results from two observational designs free of immortal time bias. Am J Respir Crit Care Med 2005; 172: 460-464.

44 Pignone M, Phillips C, Mulrow C. Use of lipid lowering drugs for primary prevention of coronary heart disease: meta-analysis of randomized trials. BMJ 2000; 321: 983-986.

45 Khurana V, Bejjanki HR, Caldito G, Owens MW. Statins reduce the risk of lung cancer in humans: a large casecontrol study of US Veterans. Chest 2007; 131: 1282-1288.

46 Hothersall E, McSharry C, Thomson NC. Potential therapeutic role for statins in respiratory disease. Thorax 2006; 61: 729-734.

47 Lee JH, Lee DS, Kim EK, et al. Simvastatin inhibits cigarette smoking-induced emphysema and pulmonary hypertension in rat lungs. Am J Respir Crit Care Med 2005; 172: 987-993.
48 Ferguson GT, Enright PL, Buist AS, Higgins MW. Office spirometry for lung health assessment in adults: A consensus statement from the National Lung Health Education Program. Chest 2000; 117: 1146-1161.

49 Eaton T, Withy S, Garrett JE, Mercer J, Whitlock RM, Rea $\mathrm{HH}$. Spirometry in primary care practice: the importance of quality assurance and the impact of spirometry workshops. Chest 1999; 116: 416-423.

50 DeJong SR, Veltman RH. The effectiveness of a CNS-led community-based COPD screening and intervention program. Clin Nurse Spec 2004; 18: 72-79.

51 Walker PP, Mitchell P, Diamantea F, Warburton CJ, Davies L., Effect of primary-care spirometry on the diagnosis and management of COPD. Eur Respir J 2006; 28: 945-952.

52 Yanbaeva DC, Dentener MA, Creutzberg EC, Wesseling G, Wouters EF., Systemic effects of smoking. Chest 2007; 131: 1557-1566.

53 Pelkonen M, Tukiainen $\mathrm{H}$, Tervahuata M, et al. Pulmonary function, smoking cessation and 30 year mortality in middle aged Finnish men. Thorax 2000; 55: 746-750.

54 Pelkonen M, Notkola IL, Tukiainen H, Tervahauta M, Tuomilehto J, Nissinen A. Smoking cessation, decline in pulmonary function and total mortality: a 30 year follow up study among the Finnish cohorts of the Seven Countries study. Thorax 2001; 56: 703-707.

55 Krahn M, Chapman KR. Economic issues in the use of office spirometry for lung health assessment. Can Respir J 2003; 10: 320-326. 